\title{
Monitoring priority substances in biota under the Water Framework Directive: how effective is a tiered approach based on caged invertebrates? A proof-of-concept study targeting PFOS in French rivers
}

\author{
Marc Babut ${ }^{1 *} \mathbb{0}$, Benoit J. D. Ferrari ${ }^{2}$, Patrick Jame ${ }^{3}$, Azziz Assoumani $^{4}$, François Lestremau ${ }^{4}$,
}

Nicolas Hette-Tronquart ${ }^{5}$, Cécile Miege ${ }^{1}$ and Olivier Perceval ${ }^{5}$

\begin{abstract}
Background: This study aims to describe and test a tiered approach for assessing compliance to Environmental Quality standards (EQSs) for priority substances in biota in line with the European Water Framework Directive. This approach is based on caged gammarids and trophic magnification factors (TMFs) at the first tier, with fish analyzed at the second tier at sites predicted to exceed the EQS at the first tier. A dataset was implemented by monitoring perfluorooctane sulfonate (PFOS) in caged gammarids exposed at 15 sites in French rivers, and in fish muscle and rest-of-body from the same sites. Isotopic ratios $\left(\delta^{13} \mathrm{C}\right.$ and $\left.\delta^{15} \mathrm{~N}\right)$ were also measured in gammarids and fish. Two scenarios were developed to compare measured PFOS concentrations in fish against predicted concentrations based on measures in caged gammarids and TMFs. Scenario (1) compared measured PFOS concentrations in fish fillets with predicted PFOS concentrations based on measured concentrations in caged gammarids and $\delta^{15} \mathrm{~N}$. Scenario (2) tested whether or not EQS exceedance was correctly predicted based on measured concentrations in caged gammarids and trophic levels (TLs) from wild fish and gammarid populations.

Results: $\delta^{13} \mathrm{C}$ and $\delta^{15} \mathrm{~N}$ variations showed that caged gammarids used local food resources during exposure in the field. PFOS concentrations in gammarids were fairly variable through time at each site. In fish, concentrations ranged from $<1$ to $250 \mathrm{ng} \mathrm{g}^{-1}$ (wet weight). After adjustment to the TL at which the EQS is set, 12 sites were above the EQS for PFOS. In scenario (1), predicted concentrations were almost correct at 7 sites out of 15. Most incorrect predictions were overestimations that were slightly improved by applying a lower (neutral) TMF. In scenario (2) we tested several variants for parameters involved in the predictions. The most efficient combination yielded two wrong predictions out of 15. This result was obtained with a higher (more conservative) TMF value, mean concentrations in gammarids from several field exposures during a year, and a TL for gammarids at the median of the distribution in French rivers.
\end{abstract}

Conclusion: The proposed tiered approach was thus efficient. However, the number of sites was relatively limited, and the dataset was biased towards EQS exceedance. The tiered approach warrants further validation.

Keywords: Water Framework Directive, Chemical status, Biota, Monitoring, Caging, Gammarus fossarum_PFOS, Compliance checking, Trophic magnification factor

\footnotetext{
*Correspondence: marc.babut@inrae.fr

1 INRAE, RIVERLY, 69625 Villeurbanne, France

Full list of author information is available at the end of the article
} 


\section{Background}

The Water Framework Directive (WFD) originally laid down a number of requirements including a periodic assessment of the 'chemical status' of European water bodies comparing the concentrations of a set of priority substances (PSs) measured in water, sediment, or biota against their respective environmental quality standards (EQSs) [1]. EQSs are thresholds defining a good chemical status based on risks to aquatic ecosystems and human health. Nevertheless, the primary EQS implementation focused on water only, as there were no EQS available at the time for the targeted PS in sediment, nor in biota.

A first set of EQSs targeting biota was introduced in 2008 in the daughter directive updating the WFD for mercury, hexachlorobenzene and hexachlorobutadiene [2]. An extended list of PS was adopted in 2013 along with the corresponding EQSs, with biota targeted for 11 PSs out of 45 [3]. Most of these chemicals are hydrophobic and prone to (or suspected of) biomagnification, presumably putting predators at risk. The European guidance issued to supporting the implementation of the 2013 directive assumed that concentrations critical to predators (or consumers) are most likely to occur in fish, with a theoretical trophic level (TL) of 4 in freshwaters and 5 in coastal waters [4]. The guidance also recommended standardizing concentrations to a lipid content of $5 \%$ for hydrophobic substances, which bioaccumulate by lipid partitioning. For mercury and perfluorooctane sulfonate (PFOS), which do not accumulate by partitioning to lipids, it was recommended to standardize concentrations to a default dry weight fraction of $26 \%$. As biota EQS values are based on either food consumption benchmarks or the secondary poisoning of piscivorous species, PS analysis should target either fillets or whole fish. Conversion factors based on regressions between fillet and whole-body concentrations can be used to translate measurements from fillet to whole-body matrix and vice versa [4].

Chemical monitoring on biota in water bodies can target species at a TL lower than 4. This situation is likely to occur in many cases, for practical (species abundance) and ethical (vertebrate sacrifice) considerations, in which case it is necessary to adjust the monitoring results to the required TL and lipid contents at which EQSs are set.

The 2013 directive authorized alternative monitoring options to fish, as long as such options provided an equivalent level of protection. To frame this possibility, the guidance document suggested implementing a tiered approach using alternative biota, such as wild crustaceans or bivalve molluscs, or other matrices, including caged organisms [4]. All these approaches are aimed at targeting sites where fish sampling would be fully justified by a risk of exceeding the EQSs, while also sparing time and resources and avoiding unnecessary fish sampling elsewhere. They all require predicting PS concentrations from field measurements in a theoretical standard fish having a TL of 4 and a lipid content of $5 \%$ (or a dry weight content of $26 \%$ ). When alternative biota are used at this screening tier, the prediction of PS concentrations in the standard fish is based on the trophic magnification factor (TMF) equation, which describes the diet-weighted average biomagnification factor of chemical residues across a food web [5].

Using caged invertebrates carries numerous advantages over sampling wild invertebrates. Besides making fieldwork more efficient, caged invertebrates allow controlling biotic confounding factors while measuring directly the bioavailable fraction of the contamination and provide robust, spatially comparable results [6-8]. Among the freshwater invertebrate species, Gammarus spp. has emerged as suitable species for this kind of monitoring. Wild gammarids have been shown to accumulate trace elements $[9,10]$ and various persistent organic chemicals [11, 12], while caged gammarids have been successfully used for monitoring trace elements and organic chemicals $[7,13,14]$. Nevertheless, strictly speaking, caged organisms do not belong to local food webs and so they cannot be assigned an actual TL.

Our purpose here is to describe a tiered approach for assessing compliance with EQSs for biota as per the European guidance requirements, using caged gammarids and selected TMFs, and to test this approach with one PS, the perfluorooctane sulfonate (PFOS) on riverine sites in France. To our knowledge, the tiered approach suggested in the European guidance [4] has never been tested in the real world at large spatial scale. Such a purpose entails addressing specific issues raised by the use of caged gammarids, such as the appropriate TL for these organisms partially disconnected from local food webs. As the ability to suitably predict either PS concentrations in fish or EQS exceedance depends also of the choices made for parameter values involved in these predictions, various options are explored and discussed.

\section{Methods}

\section{Tiered approach concept}

Figure 1 below summarizes the proposed monitoring strategy for PSs in biota. It involves caged organisms at the first tier (screening) with PS concentrations measured in fish at tier \#2 if tier \#1 results predict EQS exceedance. Conservative options should be preferred at tier \#1, in order to minimize type II errors (or false negatives). 
Tier \#1 (screening)

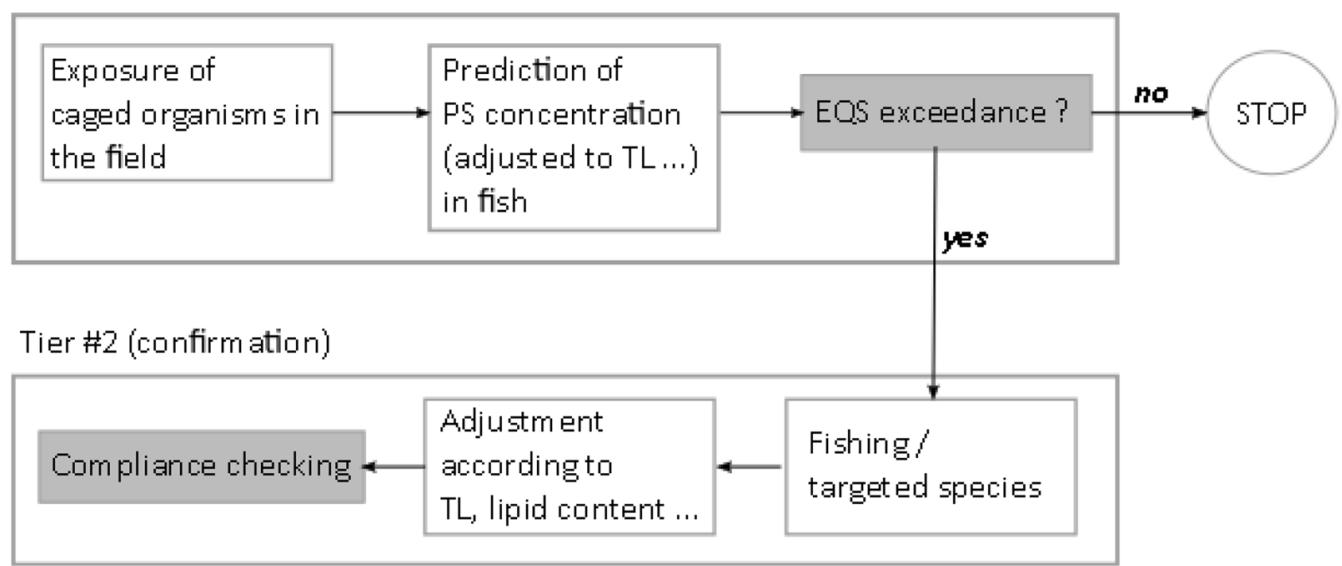

Fig. 1 Schematic flowchart of the biota monitoring approach using caged organisms

Tier \#1—screening monitoring sites for probable compliance with biota EQSs

Caging is carried out according to the French standard method "Water quality-in situ Gammarus caging for measuring bioaccumulation of chemical substances" [15]. Briefly, pools of male gammarids of a specific size class $(\approx 2 \mathrm{~mm})$ and originating from a unique wild population from a (pristine) reference site are introduced at monitored sites in polypropylene containers pierced with $1 \mathrm{~mm}$ holes, thus allowing water, suspended particles and small organisms to flow through. The devices are left on site for 3 weeks, and gammarids are not fed during this period. At the end of exposure, the cages are retrieved, packed in cool boxes maintained at $4{ }^{\circ} \mathrm{C}$ and sent to the laboratory within $24 \mathrm{~h}$. Gammarids are then pooled and processed for analysis. One measured concentration $\left(C_{i}\right.$ gam) is thus available for each PS at each site.

Predicted concentrations in fish $\left(C_{i}\right.$ fish) are estimated according to Eq. 1, adapted from the European guidance for biota monitoring [4]:

$$
C_{i} f i s h=C_{i} \text { gam } \times \mathrm{TMF}_{i}\left(\mathrm{TL}_{f i s h}-\mathrm{TL}_{\mathrm{gam}}\right),
$$

where $\mathrm{TMF}_{i}$ is the TMF selected for priority substance $i$, and $\mathrm{TL}_{\text {fish }}$ and $\mathrm{TL}_{\text {gam }}$ point to trophic levels (TLs) assigned to fish and caged gammarids, respectively. $C_{i}$ designates the predicted whole-body concentration in fish $\left(C_{i}\right.$ fish) or the measured concentration in gammarids $\left(C_{i}\right.$ gam). Note that this equation is consistent with the generic trophic magnification model, which for hydrophobic substances is based on concentrations in lipids $[16,17]$.

Note too that estimating TLs is not strictly required, provided than $\delta^{15} \mathrm{~N}$ measurements are available [17], in which case TLs in Eq. 1 are replaced by the respective $\delta^{15} \mathrm{~N}$ values divided by 3.4, i.e., the mean trophic fractionation of $\delta^{15} \mathrm{~N}$ [18].

A mean TL based on homologous local species is assigned to caged gammarids. As mentioned above, a value of 4 should be used for $\mathrm{TL}_{\mathrm{fish}}$ in freshwaters so as to predict EQS exceedance. Compliance to EQS will be checked by comparing the geometric mean of measured concentrations (and the geometric standard deviation) or the concentration in a pooled sample against the EQS [4].

As few of the fish species selected for monitoring PSs in biota are expected to present the theoretical TL of 4, measured concentrations need to be adjusted at this TL using Eq. 2 [4], which is derived from the above-mentioned trophic magnification model:

$$
C_{\mathrm{TL} \text {-adjusted }}=C_{\text {measured }} * \mathrm{TMF}^{\left(4-\mathrm{TL}_{x}\right)},
$$

where $x$ is the species monitored and $C$ are the concentrations. TL and TMF were defined previously.

As stated above, $\mathrm{EQS}_{\text {biota }}$ generally refer to organisms that have a mean lipid content of $5 \%$. Measured concentrations should therefore be adjusted to this lipid content prior to being compared to $\mathrm{EQS}_{\text {biota. }}$. For PSs such as mercury or PFOS that do not accumulate via partitioning to lipids, the guidance recommends by default an adjustment to a standard dry weight of $26 \%$ (Eq. 3; [4]):

$$
\text { conc }_{\text {adjusted }}=\text { conc }_{\text {measured }} \times \frac{0.26}{\text { measured dry weight }} .
$$

Tier \#2-confirming exceedance of biota EQSs by sampling and analyzing target fish species

Fish would be collected and analyzed at sites where predicted $C_{i}$ fish would exceed one or several biota EQSs. 
The guidance document [4] states that two species, representing different habitats and feeding conditions and different bioaccumulation capacities, should be selected. In France, this has led to selecting barbel (Barbus barbus) and chub (Squalius cephalus). Roach (Rutilus rutilus) could be used instead of barbel at sites (catchments) where barbel is rare or absent.

The above-mentioned guidance leaves the options open for analyzing individuals or pools, while outlining advantages and disadvantages of both. The option currently selected in France is to analyze one pool of about ten individuals of the same species and same size class per sampling event. Compliance with EQSs would follow the same rules as explained above.

\section{Study design}

Fifteen sites were selected from the current French river monitoring network. Selection criteria included biota availability and anthropogenic pressures in order to get a gradient of contamination by PSs.

Caged gammarids were exposed at these 15 sites throughout France for 3 weeks as per the existing guideline [15], at three successive periods in 2018 (June, September and November). Site characteristics are presented in Additional file 1: Table S1.

Fish were caught by electrofishing between the end of June and the end of November 2018, targeting either chub (Squalius cephalus), barbel (Barbus barbus) or roach (Rutilus rutilus). They were euthanatized on site with an excess dose of eugenol, in adherence with current ethical rules. Fifteen pools of 8 to 11 individuals of the same species and belonging to the same size class (Additional file 1: Table S2) were put together and taken to the laboratory in cool boxes for dissection and analysis.

\section{Analysis}

Details on analytical protocols are provided in SM, section II.

\section{Isotopic ratios}

Finely ground gammarid samples of about $0.5 \mathrm{mg}$ dry weight $(\mathrm{dw})$ each were placed and weighed in tin capsules, then injected into a helium flow, with a limited quantity of oxygen $\left(\mathrm{O}_{2}\right)$ into a combustion unit $\left(950{ }^{\circ} \mathrm{C}\right)$. Gases passed first through a copper oven $\left(650{ }^{\circ} \mathrm{C}\right)$ so as to reduce nitrogen oxides into nitrogen $\left(N_{2}\right)$ and capture the excess $\mathrm{O}_{2}$, and then into a cold tube containing magnesium perchlorate to trap the remaining water. $\mathrm{N}_{2}$ and $\mathrm{CO}_{2}$ gases were finally separated on a chromatographic column and injected into an isotopic mass spectrometer. Results are expressed as $\delta^{13} \mathrm{C}$ or $\delta^{15} \mathrm{~N}$, i.e., the ratio of $\left[{ }^{13} \mathrm{C}\right] /\left[{ }^{12} \mathrm{C}\right]$ or $\left[{ }^{15} \mathrm{~N}\right] /\left[{ }^{14} \mathrm{~N}\right]$ in the sample to that of a reference sample (SM, section II.1). Isotopic ratio measurement in fish samples (i.e., fillets) followed the same procedure as that applied to caged gammarids. For both $\delta^{13} \mathrm{C}$ and $\delta^{15} \mathrm{~N}$, standard deviations of the value for gammarids and fish were calculated on two measurements, when the gap between these two values was $<0.60$ $\delta$. Above this gap, a third measurement was done and accounted for in the standard deviation (SD) calculation. SD values ranged between 0.01 and 0.43 , and between 0.01 and 1.16 for $\delta^{13} \mathrm{C}$ and $\delta^{15} \mathrm{~N}$, respectively.

\section{PFOS}

PFOS was analyzed in gammarids and fish tissues, i.e., fillets and "rest of body" (ROB), following a modified Aquaref MA46 method [19]. Samples were first freezedried and finely ground. Internal standards and methanol $(10 \mathrm{~mL})$ were then added to an aliquot $(1 \mathrm{~g})$ of the resulting powder. Next followed a purification process involving activated carbon, evaporation and re-dissolution in acetonitrile. PFOS was analyzed by high-pressure liquid chromatography on a C18 column followed by tandem mass spectrometry (electro-spray ionization, negative mode). Injection blanks, calibration, method controls and methods blanks were used throughout the analytical process so as to check for absence of system contamination, trueness and signal drift. The limit of quantification (LQ) was determined according to French Standard NF T90-210 (details in SM, section II.2). Briefly, first, two candidate LQs were estimated based on the signalto-noise ratio, then 20 blank tissue samples were spiked at the concentration level of the two candidate LQs (10 samples for each candidate LQ), and then analyzed. The candidate LQ was validated if the average determined concentration, including its uncertainty, was between 40 and $160 \%$ of the spiked target concentration.

\section{TMF selection}

TMFs are obtained by regression between the chemical concentrations in organisms of a food web and their respective TLs [5]; in principle, all concentrations refer to whole-body. The TMFs used for the tests were taken from previous studies on French riverine sites [20, 21]; while they came from field studies in a context relevant to the purpose of the present study, they were comparable to the TMFs retrieved from a literature review and screened according to Kidd et al. [17]. The TMFs determined in French rivers are compiled in Additional file 1: Table S4, and TMFs from the literature survey are compiled in Additional file 1: Figure S1 and Table S5. Two TMF values were selected for the predictive tests: the median $\left(\mathrm{TMF}_{50}\right)$ and third quartile $\left(\mathrm{TMF}_{75}\right)$ derived from the 6 TMFs for French riverine sites (Additional file 1: Table S4). While $\mathrm{TMF}_{50}$ is a priori neutral in terms of risk, $\mathrm{TMF}_{75}$ represents a more conservative option, both 
for the adjustment of concentrations measured in fish and for the prediction based on concentrations in caged gammarids. $\mathrm{TMF}_{75}$ was preferred to an even more conservative option such as the 90th percentile due to the limited number of TMFs available.

\section{Prediction of fish contamination on the basis of caged organisms and TMFs-test design}

The PFOS concentrations predicted in fish muscle (fillet) according to Eq. 1 were compared against measured concentrations in this tissue (scenario \#1). The predictions were based on PFOS concentrations in caged gammarids (September campaign), TMF values, and $\delta^{15} \mathrm{~N}$ measured in caged gammarids $\left(\delta^{15} \mathrm{~N}_{\text {gam }}\right)$ and fish $\left(\delta^{15} \mathrm{~N}_{\text {fish }}\right)$. The slope of the regression between fillet and whole-body concentrations was used to convert the predicted wholebody concentrations to predicted fillet concentrations (Eq. 4, derived from Eq. 1; details in SM, section III); this conversion stems from the fact that the EQS for PFOS was derived from a benchmark targeting human health and fish consumption. The predictions were deemed correct if the concentration ranges were similar:

$$
C_{\text {fish-fillet }}=\frac{C_{\text {gam }} \times \operatorname{TMF}\left(\left(\delta^{15} N_{\text {fish }}-\delta^{15} N_{\text {gam }}\right) / 3.4\right)}{\text { slope }}
$$

where $C_{\text {fish-fillet }}$ is predicted PFOS concentration in fish fillet, $C_{\text {gam }}$ is measured PFOS concentration in gammarids, and slope is slope of the regression between PFOS concentrations measured in fillets and in whole fish.

Scenario \#2 aimed to check whether the predicted concentrations were correct in terms of EQS exceedance. Prediction of EQS exceedance entailed adjusting the predicted whole-body concentrations in fish to $\mathrm{TL}=4$ before estimating the corresponding concentrations in fillets (Eq. 5, derived from Eq. 2):

$$
C_{\text {ff-TL-adj }}=\frac{C_{\text {gam }} \times \mathrm{TMF}^{\left(4-\mathrm{TL}_{\mathrm{gam}}\right)}}{\text { slope }}
$$

where $C_{\mathrm{ff}-\mathrm{TL}-\mathrm{adj}}$ is predicted PFOS concentration in fillet of a fish at $\mathrm{TL}=4$ according to Eq. 2, using TLs collected from FishBase [22]. This predicted PFOS concentration is compared against the measured PFOS concentrations adjusted to $\mathrm{TL}=4$ according to Eq. 2 . $\mathrm{TL}_{\text {gam }}$ is the TL assigned to caged gammarids, assuming they hold a similar trophic position to that of wild populations.

Both scenarios are summarized in Fig. 2.

Several options were used in each scenario for TMF values $\left(\mathrm{TMF}_{50}, \mathrm{TMF}_{75}\right)$, for slope of the regression between fillet and whole-body concentrations in fish, and for TLs (fish and gammarids). For PFOS concentrations in gammarids, we used either the results from the September campaign (close to fish capture) or the arithmetic mean of two or three campaigns.

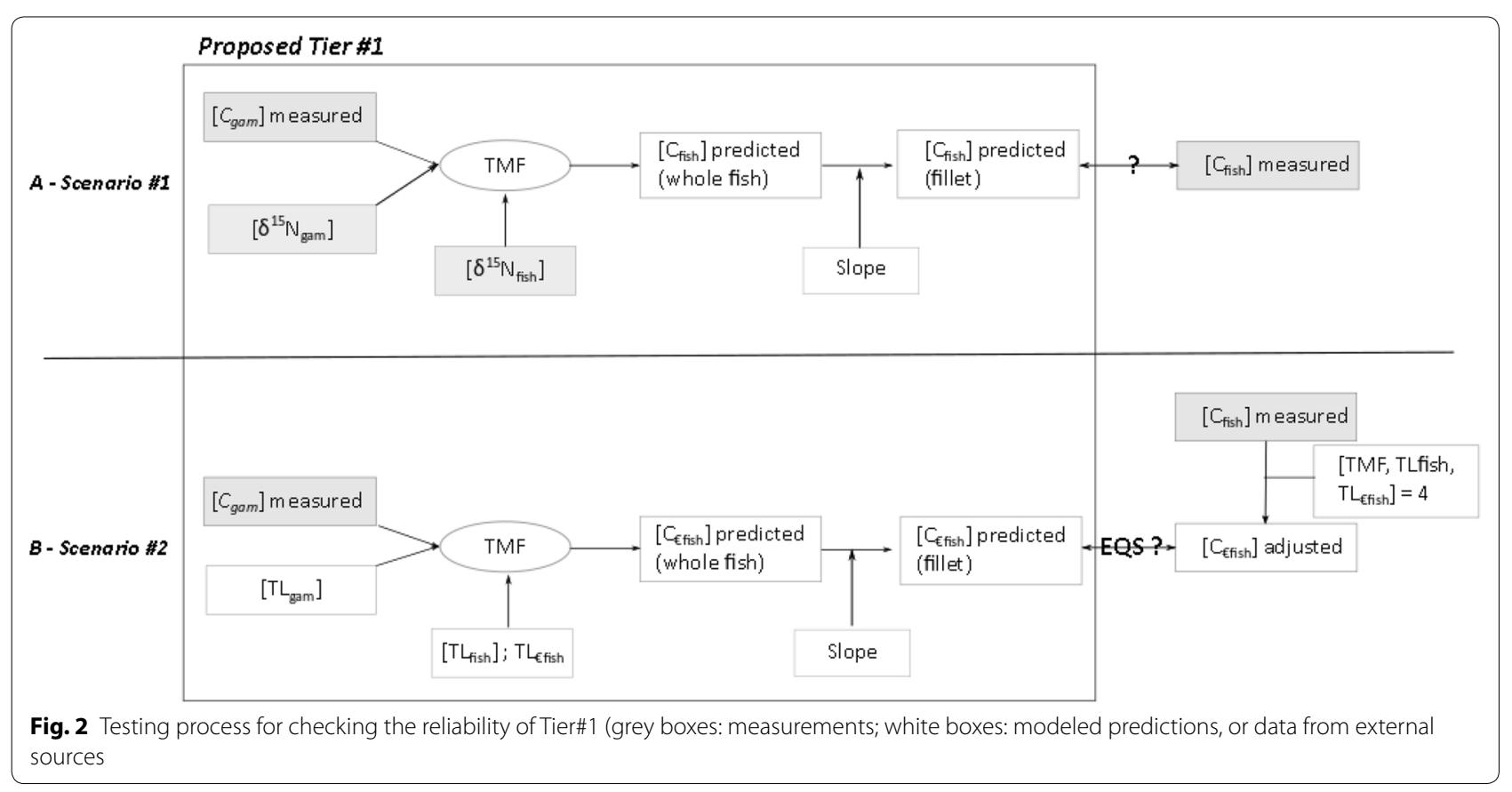




\section{Data processing and statistics}

Relationships between fillet and whole-body concentrations were assessed by Theil-Sen regression with using Pro-UCL 5.1 software [23], to include censored data in the datasets with Mann-Kendall tests applied prior to these regressions in order to check for the trend.

Multiple sets were compared using non-parametric Kruskal-Wallis tests followed by post hoc Dunn tests (Pro-UCL 5.1 software or XLStat v19.4). Significance was set at $\alpha=0.05$ in all tests.

\section{Results}

Gammarids were successfully exposed in the field and retrieved at three periods of the year; 43 samples were collected as two samples were lost at the same site (September and November campaigns). Survival rates ranged between 16 and 72\% in June, 25 and 56\% in September, and 42 and $66 \%$ in November, but enough quantities were collected sufficient for analyzing PFOS and isotopic ratios in all samples. Fifteen fish samples were collected (Additional file 1: Table S2): 13 chub, one barbel and one roach. All the data presented in the next section is available online $[24,25]$.

\section{Isotopic ratios}

Ranges of $\delta^{13} \mathrm{C}$ and $\delta^{15} \mathrm{~N}$ values for caged gammarids from June (campaign \#1) to November (campaign \#3) 2018 are reported in Fig. 3. Both isotopic ratios were significantly higher (for all sites pooled and almost systematically at each site) in November than in the two other campaigns. These variations added to the seasonal variations of isotopic ratios in gammarids at the site providing organisms for caging, i.e., a shift towards lower $\delta^{13} \mathrm{C}$ values in spring and towards slightly higher $\delta^{15} \mathrm{~N}$ values in autumn/winter (section $\mathrm{V}$ - Additional file 1: Figure S2). Variations during caging was calculated on initial (T0) values in June, September and November (SM, section V).

Both isotopic ratios changed in caged gammarids throughout the field exposure period. $\delta^{13} \mathrm{C}$ changes were variable among sites in June and September, with no discernible consistent pattern (Additional file 1: Figure S2). In November, $\delta^{13} \mathrm{C}$ values became less negative during field exposure at almost all sites. $\delta^{15} \mathrm{~N}$ values during field exposure increased at all sites but two in all three campaigns (Additional file 1: Figure S3). These changes in isotopic ratios suggest that the caged gammarids exploited local food sources during field exposure, leading to a slightly higher $\delta^{15} \mathrm{~N}$ value (mean gain $\approx 1 \%$ ) at most sites. The very nature of the food items consumed by caged gammarids also appears quite different in November, as shown by the positive variations of $\delta^{13} \mathrm{C}$ values contrasting with the more diverse variations in the June and September campaigns.

In fish, $\delta^{13} \mathrm{C}$ ranged between -28.46 and $-22.21 \%$, whereas $\delta^{15} \mathrm{~N}$ varied between 9.10 and 16.77. The lowest $\delta^{15} \mathrm{~N}$ values were observed at sites 09 and 10 , which are presumably less subject to anthropogenic pressures. The highest $\delta^{15} \mathrm{~N}$ value was at site 05 , which is located downstream from a densely populated watershed hosting numerous industries, as well as intensive agriculture.

Trophic levels in wild Gammarus spp. ranged from 1.26 to 2.91 (Additional file 1: Figure S4 and Table S6, data from Hette-Tronquart and Belliard [26]. In scenario \#2, we used both the 75 th percentile (2.28) and the median (2.00).
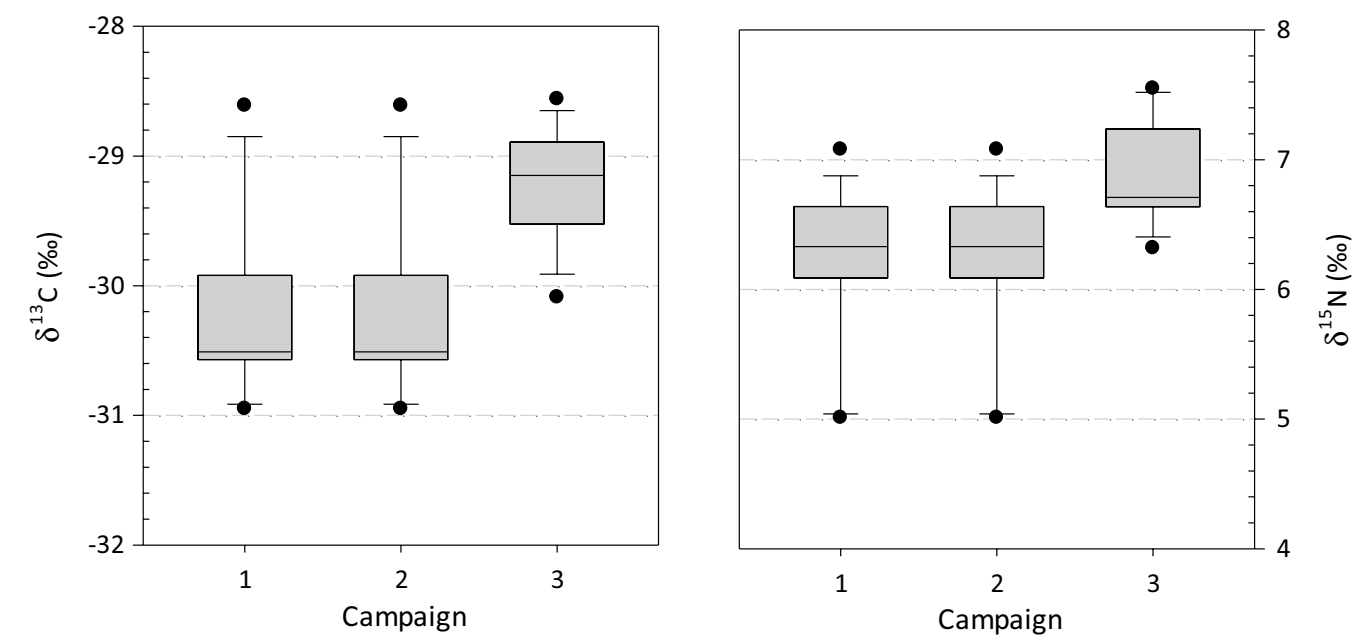

Fig. 3 Distributions of $\delta^{13} \mathrm{C}$ and $\delta^{15} \mathrm{~N}$ values in caged organisms at 15 sites in June (1), September (2) and November (3) 2018 


\section{Contamination ranges \\ Caged organisms}

PFOS was quantified in $80-87 \%$ of caged organism samples from June and September campaigns, respectively, but only $47 \%$ of samples from the November campaign. Concentrations ranges were nevertheless similar among the three campaigns, reaching 22.7, 22.5 and $17.3 \mathrm{ng} \mathrm{g}^{-1}$ ww in June, September and November, respectively.

PFOS levels in gammarids were fairly variable through time at each site, and no specific pattern could be identified (Additional file 1. Figure S5 part A).

\section{Fish}

PFOS was quantified in $77 \%$ of fish fillet or ROB samples. PFOS concentrations in fillet ranged from $<\mathrm{LQ}$ to $250 \mathrm{ng} \mathrm{g}^{-1} \mathrm{ww}$. For 11 out of 15 pooled fish samples, PFOS was quantified in both fillets and ROB; for the four remaining pools, PFOS concentrations were $<\mathrm{LQ}$ in fillets, or ROB, or both. For these four samples, it was therefore impossible to determine whole-fish concentrations as detailed in SM, section III. Weighted mean concentrations in whole fish thus ranged from undetermined to $553 \mathrm{ng} \mathrm{g}^{-1} \mathrm{ww}$. The current EQS (9.1 $\left.\mathrm{ng} \mathrm{g}^{-1} \mathrm{ww}\right)$, which was derived from a benchmark for human food consumption [27] and thus applies to fillet, was exceeded at two sites while a third site displayed a concentration at the EQS (Additional file 1: Figure S5 part B). Note that this classification is not a consistent compliance check, as no adjustment was made according to TL or dry weight content.

A Theil-Sen regression including all 15 sample pairs yielded a slope of 2.202 , with a $95 \%$ confidence interval from 1.800 to 2.671 (intercept $-1.675 ; p \approx 0.00004$; SM, section III). This slope is very close to the value obtained with a linear regression accounting for uncensored values only (slope of $2.20 \pm 0.01$; intercept $-0.318 \pm 0.665$; $\left.R^{2}=1.000, p<0.0001\right)$, although this regression was strongly influenced by the extremely high concentrations measured in fish from site 05 . The Theil-Sen regression appears thus more robust. This result is also close to the slope found in a study on the same fish species (barbel and chub) in a few French rivers, but different from the slopes found in Lake Geneva (Additional file 1: Table S3).

\section{Prediction of PFOS concentrations in fish}

Comparison of predicted and measured PFOS concentrations (scenario \#1)

Predicted concentrations in fish fillets based on concentrations in caged gammarids from the September campaign are reported in Table 1 . This prediction was impossible for sites 01 and 11, where PFOS was $<$ LQ in caged gammarids. As expected, predicted concentrations were lower when based on $\mathrm{TMF}_{50}$ than on $\mathrm{TMF}_{75}$, while using the lower bound of the confidence interval of the slope led to higher predicted concentrations, and vice versa.

Table 1 Predicted and measured PFOS concentrations (ng $\mathbf{g}^{-1} \mathbf{w w}$ ) in fish fillets based on the September campaign (nd: not determined)

\begin{tabular}{|c|c|c|c|c|c|c|c|}
\hline \multirow[t]{3}{*}{ Site } & \multicolumn{6}{|c|}{ Predicted concentrations calculated with } & \multirow{3}{*}{$\begin{array}{l}\text { Measured } \\
\text { concentrations } \\
\text { (fish fillet) }\end{array}$} \\
\hline & \multicolumn{2}{|c|}{ Median slope } & \multicolumn{2}{|c|}{ Upper bound (CI 95\%) of slope } & \multicolumn{2}{|c|}{ Lower bound (Cl 95\%) of slope } & \\
\hline & $\mathrm{TMF}_{75}$ & $\mathrm{TMF}_{50}$ & $\mathrm{TMF}_{75}$ & $\mathrm{TMF}_{50}$ & $\mathrm{TMF}_{75}$ & $\mathrm{TMF}_{50}$ & \\
\hline 01 & nd & nd & nd & nd & nd & nd & 3.88 \\
\hline 02 & 19.6 & 15.1 & 16.17 & 12.42 & 23.10 & 17.74 & 10.5 \\
\hline 03 & 11.6 & 9.15 & 9.53 & 7.54 & 13.62 & 10.76 & 8.89 \\
\hline 04 & 8.60 & 7.08 & 7.08 & 5.83 & 10.11 & 8.33 & 252 \\
\hline 05 & 310 & 203 & 256 & 168 & 365 & 239 & 7.86 \\
\hline 06 & 16.1 & 12.7 & 13.2 & 10.5 & 18.9 & 14.9 & 3.45 \\
\hline 07 & 5.43 & 4.34 & 4.47 & 3.57 & 6.39 & 5.10 & 3.48 \\
\hline 08 & 6.59 & 5.30 & 5.43 & 4.36 & 7.75 & 6.23 & $<\mathrm{LQ}$ \\
\hline 09 & 4.37 & 3.55 & 3.60 & 2.93 & 5.14 & 4.18 & 6.03 \\
\hline 10 & 3.71 & 3.33 & 3.06 & 2.74 & 4.37 & 3.92 & $<L Q$ \\
\hline 11 & nd & nd & nd & nd & nd & nd & $<\mathrm{LQ}$ \\
\hline 12 & 4.11 & 3.16 & 3.38 & 2.60 & 4.83 & 3.72 & 4.64 \\
\hline 13 & 24.6 & 18.9 & 20.3 & 15.5 & 28.9 & 22.2 & 3.43 \\
\hline 14 & 41.8 & 32.4 & 34.4 & 26.7 & 49.2 & 38.1 & 7.97 \\
\hline 15 & 22.8 & 17.6 & 18.8 & 14.5 & 26.8 & 20.6 & 3.81 \\
\hline
\end{tabular}


Sites 04 and 05 are clearly outliers, with either predicted concentrations well below the measured ones, or vice versa. In the case of site 04 , this discrepancy is due to the very high PFOS concentration in fish, which contrasts with a concentration in the lower range of PFOS concentrations in gammarids in the September campaign. In the case of site 05 , the very high predicted PFOS concentration results from the combination of a high caged gammarid PFOS concentration and a high $\delta^{15} \mathrm{~N}$ in fish.

Six other sites $(02,06,08,13,14,15)$ gave predicted concentrations well above the measured ones, whatever the TMF used, except for the variant combining $\mathrm{TMF}_{50}$ and the upper bound of the slope confidence interval at site 02 . Four sites $(03,07,09,12)$ showed near overlap between measured and predicted levels. For the three remaining sites $(01,10,11)$, PFOS was $<$ LQ in gammarids, making it impossible to predict concentrations in fish, but the corresponding measured PFOS concentrations in fish were either low or $<$ LQ. In summary, predicted concentrations were almost correct at seven sites $(01,03,07,09,10,11$, and 12) out of 15 . Most of the incorrect predictions were overestimations that were slightly improved by applying $\mathrm{TMF}_{50}$ instead of $\mathrm{TMF}_{75}$.

When the 95\% upper confidence limit of the regression slope was applied instead of the median slope to convert whole-fish to fillet concentrations, predicted concentrations were lower. Nevertheless, this did not substantially improve overall prediction accuracy. Predicted concentrations at sites $02,06,08,13,14$ and 15 remained well above the measured concentrations. Predicted concentrations at sites 03 and 07 remained close to measured concentrations, while at sites 09 and 12 they were slightly more underestimated than previously. Since the intercept of the regression between fillet and whole-fish concentrations was negative, introducing it in the prediction would increase the predicted concentrations, thus increasing the overestimation for sites $02,06,08,13,14$ and 15 . We therefore did not explore further this option in any scenarios. Similar conclusions can be drawn when applying the lower bound of the slope confidence interval.

\section{Predicted PFOS concentrations vs EQS exceedance (scenario \#2)}

Four sets of concentrations adjusted to the TL at which the EQS is set were calculated based on Eqs. 2 and 3, using either $\mathrm{TMF}_{75}$ or $\mathrm{TMF}_{50}$ (Table 2), and TLs obtained from FishBase [22], and with or without adjustment to mean dry weight contents (Table 2). The TL values varied from 2.7 ( $S$. cephalus) at sites $01,03,04,05,06,07,08,09,10,11,13,14$ and 15 , to 3.0 ( $R$. rutilus) at site 12 and 3.1 (B. barbus) at site 02 . Weighted mean dry weight contents for fish are reported Additional file 1: Table S2. These calculations
Table 2 Measured/adjusted PFOS concentrations in fish fillet (nd not determined)

\begin{tabular}{|c|c|c|c|c|c|}
\hline \multirow[t]{3}{*}{ Site } & \multirow{3}{*}{$\begin{array}{l}\text { Measured PFOS } \\
\text { conc. (fillet) }\end{array}$} & \multicolumn{4}{|c|}{ Adjusted PFOS concentrations (fillet) } \\
\hline & & \multicolumn{2}{|c|}{$\begin{array}{l}\text { No adjustment } \\
\text { to dry weight } \\
\text { content }\end{array}$} & \multicolumn{2}{|c|}{$\begin{array}{l}\text { Adjusted to dry } \\
\text { weight content }\end{array}$} \\
\hline & & $\mathrm{TMF}_{75}$ & $\mathrm{TMF}_{50}$ & $\mathrm{TMF}_{75}$ & $\mathrm{TMF}_{50}$ \\
\hline 01 & 3.88 & 16.0 & 13.4 & 19.6 & 16.4 \\
\hline 02 & 10.5 & 28.1 & 24.9 & 27.9 & 24.7 \\
\hline 03 & 8.89 & 36.7 & 30.8 & 44.2 & 37.1 \\
\hline 04 & 252 & 1039 & 872 & 1323 & 1110 \\
\hline 05 & 7.86 & 32.4 & 27.2 & 41.9 & 35.2 \\
\hline 06 & 3.45 & 14.3 & 12.0 & 17.6 & 14.8 \\
\hline 07 & 3.48 & 14.4 & 12.0 & 17.3 & 14.5 \\
\hline 08 & $<L Q$ & nd & nd & nd & nd \\
\hline 09 & 6.03 & 24.9 & 20.9 & 29.4 & 24.7 \\
\hline 10 & $<L Q$ & nd & nd & nd & nd \\
\hline 11 & $<L Q$ & nd & nd & nd & nd \\
\hline 12 & 4.64 & 13.8 & 12.1 & 15.0 & 13.1 \\
\hline 13 & 3.43 & 14.1 & 11.9 & 16.0 & 13.4 \\
\hline 14 & 7.97 & 32.9 & 27.6 & 34.0 & 28.5 \\
\hline 15 & 3.81 & 15.7 & 13.2 & 18.3 & 15.4 \\
\hline
\end{tabular}

led to higher predicted PFOS concentrations in fish fillets at all sites. Consequently, the number of samples exceeding the EQS of $9.1 \mathrm{ng} \mathrm{g}^{-1} \mathrm{ww}$ rose to 12 , whatever the TMF applied (Table 2). We kept only the concentrations unadjusted to dry weight contents for the sake of comparison with predicted concentrations.

The selected adjusted-measured concentrations were compared against predicted concentrations (example in Table 3, based on concentrations in gammarids and the median slope of the regression between fillet and wholebody concentrations). Type II errors (or false negatives) occurred when the predicted concentration was below the EQS, while the adjusted concentration was above; the opposite situation yielded type I errors (false positives).

In this example, seven to nine fish samples were predicted to exceed the EQS for PFOS depending on the TMF applied, resulting in zero to one type I and four to five type II errors. The type II errors occurred mainly at sites where measured concentrations in gammarids were low or $<$ LQ.

Using the 95\% upper confidence limit of the slope instead of the central value yielded the same number of type II errors when using $\mathrm{TMF}_{75}$, and no type I errors. In the $\mathrm{TMF}_{50}$-based variant, overall number of errors rose to 6 , due to type II errors only. Conversely, using the $95 \%$ lower confidence limit of the slope yielded similar results to using the median slope, with four type II errors and one type I error for $\mathrm{TMF}_{75}$ and $\mathrm{TMF}_{50}$. 
Table 3 Type I and type II errors $(0=$ correct; $1=$ error; the third and sixth columns report whether the prediction of EQS exceedance was correct, i.e., 0 , or erroneous, i.e., 1) in scenario \#2: variant using a single field campaign with caged gammarids, and the median slope of the regression between fillet and whole-body concentrations

\begin{tabular}{|c|c|c|c|c|c|c|}
\hline \multirow[t]{2}{*}{ Site } & \multicolumn{3}{|c|}{$\mathrm{TMF}_{75}$} & \multicolumn{3}{|c|}{$\mathrm{TMF}_{50}$} \\
\hline & Err. I & Err. II & Overall & Err. I & Err. II & Overall \\
\hline 01 & 0 & 1 & 1 & 0 & 1 & 1 \\
\hline 02 & 0 & 0 & 0 & 0 & 0 & 0 \\
\hline 03 & 0 & 0 & 0 & 0 & 1 & 1 \\
\hline 04 & 0 & 0 & 0 & 0 & 0 & 0 \\
\hline 05 & 0 & 0 & 0 & 0 & 0 & 0 \\
\hline 06 & 0 & 0 & 0 & 0 & 0 & 0 \\
\hline 07 & 0 & 1 & 1 & 0 & 1 & 1 \\
\hline 08 & 0 & 0 & 0 & 0 & 0 & 0 \\
\hline 09 & 0 & 1 & 1 & 0 & 1 & 1 \\
\hline 10 & 1 & 0 & 1 & 0 & 0 & 0 \\
\hline 11 & 0 & 0 & 0 & 0 & 0 & 0 \\
\hline 12 & 0 & 1 & 1 & 0 & 1 & 1 \\
\hline 13 & 0 & 0 & 0 & 0 & 0 & 0 \\
\hline 14 & 0 & 0 & 0 & 0 & 0 & 0 \\
\hline 15 & 0 & 0 & 0 & 0 & 0 & 0 \\
\hline Total & 1 & 4 & 5 & 0 & 5 & 5 \\
\hline
\end{tabular}

Table 4 Results obtained in scenario \#2 according to Eq. 5 parameter variants. $C_{\text {gam }}$ is the concentration measured in caged gammarids, slope is the slope of the regression between fish fillet and whole-body concentrations, and $\mathrm{TL}_{\mathrm{gam}}$ is the trophic level assigned to caged gammarids

\begin{tabular}{|c|c|c|c|c|c|c|}
\hline TMF & $C_{g a m}$ & Slope & $\mathrm{TL}_{\text {gam }}$ & NType I & NType II & Correct \\
\hline $\mathrm{TMF}_{50}$ & 1 campaign (Sep) & Lower bound & 75th percentile & 1 & 4 & 10 \\
\hline $\mathrm{TMF}_{50}$ & 1 campaign (Sep) & Median & 75th percentile & 0 & 5 & 10 \\
\hline $\mathrm{TMF}_{50}$ & 1 campaign (Sep) & Upper bound & 75th percentile & 0 & 6 & 9 \\
\hline $\mathrm{TMF}_{50}$ & 2 campaigns (June-Sep) & Lower bound & 75th percentile & 1 & 4 & 10 \\
\hline $\mathrm{TMF}_{50}$ & 2 campaigns (June-Sep) & Median & 75th percentile & 0 & 5 & 10 \\
\hline $\mathrm{TMF}_{50}$ & 2 campaigns (June-Sep) & Upper bound & 75th percentile & 0 & 5 & 10 \\
\hline $\mathrm{TMF}_{50}$ & 3 campaigns & Lower bound & 75th percentile & 0 & 4 & 11 \\
\hline $\mathrm{TMF}_{50}$ & 3 campaigns & Median & 75th percentile & 0 & 5 & 10 \\
\hline $\mathrm{TMF}_{50}$ & 3 campaigns & Upper bound & 75th percentile & 0 & 5 & 10 \\
\hline $\mathrm{TMF}_{75}$ & 1 campaign (Sep) & Lower bound & 75th percentile & 1 & 4 & 10 \\
\hline $\mathrm{TMF}_{75}$ & 1 campaign (Sep) & Median & 75th percentile & 1 & 4 & 10 \\
\hline $\mathrm{TMF}_{75}$ & 1 campaign (Sep) & Upper bound & 75th percentile & 0 & 4 & 11 \\
\hline $\mathrm{TMF}_{75}$ & 2 campaigns (June-Sep) & Lower bound & 75th percentile & 1 & 1 & 13 \\
\hline $\mathrm{TMF}_{75}$ & 2 campaigns (June-Sep) & Lower bound & Median & 2 & 0 & 13 \\
\hline $\mathrm{TMF}_{75}$ & 2 campaigns (June-Sep) & Median & 75th percentile & 1 & 3 & 11 \\
\hline $\mathrm{TMF}_{75}$ & 2 campaigns (June-Sep) & Upper bound & 75th percentile & 0 & 5 & 10 \\
\hline $\mathrm{TMF}_{75}$ & 3 campaigns & Lower bound & 75th percentile & 1 & 1 & 13 \\
\hline $\mathrm{TMF}_{75}$ & 3 campaigns & Lower bound & Median & 2 & 0 & 13 \\
\hline $\mathrm{TMF}_{75}$ & 3 campaigns & Median & 75th percentile & 0 & 3 & 12 \\
\hline $\mathrm{TMF}_{75}$ & 3 campaigns & Upper bound & 75th percentile & 0 & 5 & 10 \\
\hline
\end{tabular}


Table 4 reports the results for scenario \#2 where several variants of each parameter of Eq. 5 were combined. For $C_{\text {gam }}$, we used either the concentrations from one campaign, or the means of two or three campaigns. For the slope, we tested the central value, and the $95 \%$ bounds of its confidence interval. For $T L_{\text {gam }}$, we took either the 75th percentile or the median of the TL distribution among 93 sites in French rivers (Additional file 1: Table S6 and Figure S4, derived from Hette-Tronquart and Belliard [26]. Median $\mathrm{TL}_{\text {gam }}$ was introduced only twice, after having identified the most efficient combination of the other parameters (TMF, $C_{\text {gam }}$ and slope).

The $\mathrm{TMF}_{50}$-based variants yielded four to six type II errors and no more than 11 correct predictions out of 15 . Results were more contrasted with $\mathrm{TMF}_{75}$, with between zero and five type II errors and few type I errors, as with $\mathrm{TMF}_{50}$. The best predictions were obtained with the association of $\mathrm{TMF}_{75}$, mean $C_{\text {gam }}$ from two or three campaigns, the lower bound of the slope confidence interval, and the median value of $\mathrm{TL}_{\text {gam }}$ distribution. An equal number of correct predictions was obtained with the 75th percentile of $\mathrm{TL}_{\text {gam }}$ distribution, two to three campaigns and the lower bound of the slope confidence interval, but with one type II error instead of zero. Environmental protection imperatives makes it is less worrying to overpredict an EQS exceedance (i.e., to commit a type I error) than to underpredict, so the variant with no type II error was slightly better.

\section{Discussion}

Exploring the effective validity of the proposed tiered approach concept entails two things: (i) addressing whether using caged organisms, especially gammarids, is a relevant solution, and (ii) examining the terms of Eq. 5 (or Eq. 4 if the purpose is to predict concentrations in fish without considering EQS exceedance). The deployment of caged gammarids has already been shown to be a robust biomonitoring tool $[7,13]$, so the question here is more about finding a sensible proxy for the TL assigned to them and justifying it (which is why this point is included in the global discussion on the terms of Eq. 5). We also discuss the first term of Eq. 5, i.e., the measured $C_{\text {fish-fillet }}$ adjusted to a standard fish, as this adjustment, and accordingly the gap to predicted concentrations, is sensitive to the values of $\mathrm{TMF}, \mathrm{TL}_{\text {fish }}$ and dry weight content.

\section{Adjustment to a standard fish}

The adjustment recommended in the EU guidance relies on three parameters, i.e., TMF, TL for fish, and dry weight content which is presented as a proxy for total protein content [4].
Dry weight contents of fish pools in this study ranged from 20.1 to $26.2 \%$ (Additional file 1: Table S2), with a median value of $21.6 \%$. Consequently, adjusting to the default dry weight content of $26 \%$ [4] increased the adjusted concentrations by $3.5-29 \%$, except at the site where the actual dry weight content of the fish sample reached $26.2 \%$. Therefore, the default dry weight content seems excessively high in our case, in contrast with a previous German study that found a relatively limited effect of standard dry weight content on adjusted PFOS concentrations in bream pools [28]. Based on our data, a standard (mean) dry weight content of $22 \%$ appears more appropriate.

Furthermore, PFOS accumulation is driven not by total protein content but by specific proteins [29-31]. These specific proteins (chiefly serum albumin and liver fatty acid-binding proteins) are not expressed to the same extent across fish species [31]. Therefore, (i) the adjustment based on a proxy for total protein content does not seem justified, and (ii) the principle of this adjustment itself appears questionable in the case of PFOS. For these reasons, the measured/adjusted concentrations in scenario \#2 were used without adjustment to dry weight contents.

TLs from FishBase [22] may also lack specificity compared to more geographically focused values. Based on a script developed for calculating the TL distribution of freshwater fish species in France [26] and the related database, we observed that median TL values for the three species studied here are higher than the respective mean TLs in FishBase (Additional file 1: Table S7). This would in turn lead to lower measured/adjusted concentrations, and possibly, to a different diagnosis of compliance with the EQS. Furthermore, using for instance the $25^{\text {th }}$ percentile of the monitored species TL distributions would have the opposite effect, which could be deemed safer, as it would lower the probability of misclassifying the sites. It would therefore be advisable to complete the European guidance on these aspects.

\section{Concentrations in gammarids}

Gammarids were successfully exposed in the field and retrieved at three periods of the year, so the current standard protocol [15] safely yields adequate materials for monitoring bioaccumulative PSs. Nevertheless, the rate of quantification was lower in the November campaign, in which the isotopic signatures of caged gammarids pointed to important changes in their food sources. We tested three options for the term $C_{\text {gam }}$, i.e., data from (a) one single campaign, or mean concentrations from (b) two or (c) three campaigns. The selection of the September campaign for option (a) was justified by its temporal proximity to the fish sampling campaign and a better 
PFOS quantification rate. Nevertheless, options (b) and (c) yielded better results for both scenarios \#1 and \#2. Due to the limited quantification rate in the November campaign, $C_{\text {gam }}$ were not significantly different between options (b) and (c). The key conclusion here is that multiple campaigns would be more representative of real fish exposure.

\section{Trophic magnification factors}

TMFs are ecosystem-specific metrics, meaning they can vary across ecosystems [5]. Conversely, it seems almost impossible to precisely characterize the ecosystems at all sites of a nationwide monitoring network. From a nationwide assessment perspective, a unique TMF value applicable at all sites seems preferable in practice, but challenging to confidently select [17]. We carefully reviewed existing TMFs for PFOS in aquatic ecosystems (Additional file 1: Table S4), and selected a set of TMFs derived from French rivers. All these TMFs were obtained in shallow freshwater ecosystems, and involved similar fish species. From this set, we derived two TMF values, i.e., the median $\left(\mathrm{TMF}_{50}\right)$ and the third quartile $\left(\mathrm{TMF}_{75}\right)$. According to Eq. 5, $\mathrm{TMF}_{75}$ is more representative of a worst-case scenario, leading to higher predicted concentrations. Using the 90th percentile of TMFs could be considered even more relevant, i.e., closer to the worst possible case, but as there were few TMF values available (Additional file 1: Table S5), $\mathrm{TMF}_{75}$ appears more robust. Nonetheless, the influence of TMF value on the fit between predicted and measured concentrations (scenario \#1) was moderate, leading to between 10 and 34\% variations in predicted concentrations (all variants taken together). In scenario \#2, using $\mathrm{TMF}_{50}$ instead of $\mathrm{TMF}_{75}$ did not substantially change the distribution between wrong and correct predictions, which seems logical: as mentioned before the TMF has also an influence on the measured/adjusted concentration, so we compared predicted against measured/adjusted concentrations based on identical TMFs on both sides of the equation. However, in this scenario \#2, no variant with $\mathrm{TMF}_{50}$ reached less than four type II errors (out of 15 sites).

\section{Trophic level of caged Gammarus spp. and fish}

In the tiered approach framework, caged organisms substitute for their local/wild homologues, in order to lower the influence of confounding factors (e.g., nutrients) on PS bioaccumulation while ensuring inter-site comparability. Caged organisms are thus implicitly assumed to occupy a similar trophic position to their wild homologues.

According to the variations of both $\delta^{13} \mathrm{C}$ and $\delta^{15} \mathrm{~N}$ during their exposure in the field, caged gammarids consumed local food items, which supports their use for monitoring bioaccumulative PSs, despite the fact that caged organisms are less connected to local food webs than their wild homologues. Moreover, caged gammarids showed very little influence of local (anthropic) nitrogen sources, unlike fish, which showed large variations in $\delta^{15} \mathrm{~N}$. This observation also argues for applying a TL derived from the TL distribution in wild gammarids. Indeed, here caged organisms were supplied by a wild population living in a pristine site, and their $\delta^{15} \mathrm{~N}$ value varied little during exposure in the field (Additional file 1: Figure S3). They were thus still close to their initial trophic position even though they could not represent the actual TL of wild gammarids at each site. Instead, they could represent a generic population.

A robust determination of TLs in fish would not be applicable in a nationwide monitoring network at tier \#1, and may even remain impracticable at tier \#2. Thus, the application of fixed TL values appears relevant in practice. Again, generic TL values derived from the TL distribution in each fish species could be sufficient for checking EQS compliance, allowing to compare the severity of contamination at a large spatial scale, while limiting the effect of confounding factors. Nevertheless, the use of TLs derived from the actual TL distributions in, e.g., large watersheds or ecoregions should be preferred to TLs from FishBase.

\section{Relationships between fish fillet and whole-body concentrations (conversion factor)}

In the case of PFOS, the EQS refers to a human-health safety limit, which makes it important to consider the relationship between the concentrations in fillet and in whole fish. Three options were examined for the slope of the regression, namely the central value (median) and the lower and upper bounds of the slope CI. Neither the median nor the upper bound provided a good predictive accuracy in scenario \#1, and the numbers of type I and type II errors were almost identical in scenario \#2. The best result was obtained with the lower bound of the slope confidence interval, which tends to increase the predicted concentrations. Combined with $\mathrm{TMF}_{75}$ and mean $C_{\text {gam }}$ (from two or three campaigns), it resulted in only two errors, either two type I and no type II, or one of each type. Because these parameter value choices both concur to increase predicted concentrations, it seems likely that caged gammarids tended to underestimate PFOS exposure for fish in the case of scenario \#2.

One important limitation of this study was that the proportion of sites presumably above the EQS was rather high, meaning that we could not check whether the approach is as equally valid for predicting compliant situations. 


\section{Conclusion}

For PFOS at least, the proposed tiered approach could work properly. Predictions at tier \#1 were quite satisfactory when applying a combination of high TMF (i.e., $\mathrm{TMF}_{75}$ ), generic TLs, and the lower bound of the slope confidence interval. However, the number of sites was relatively limited, and the dataset was biased towards EQS exceedance. Further validation of the tiered approach for checking the compliance with EQSs for biota are still needed and should involve more sites covering a larger PFOS contamination gradient, as well as other PSs that behave differently to PFOS. Moreover, improvements are also needed for assigning appropriate TLs for the targeted fish species in the different catchments of concern.

\section{Supplementary information}

Supplementary information accompanies this paper at https://doi. org/10.1186/s12302-020-00416-4.

Additional file 1: Table S1. Site characteristics (site codes point to registries of river monitoring sites: the first two digits correspond to regions/ basins where sites are located). Table S2. Characteristics of fish pool samples: number of individuals in the pool (sample size), individual size and mass ranges, dry weight content (MS \%) for muscle, rest-of-body (ROB) and whole fish (weighted mean MS\%). Table S3. Compilation of fillet-toWB regression parameters from various datasets (values between brackets point to the 95\% confidence level bounds). Table S4. TMFs for PFOS at French riverine sites. Table S5. Other TMF values for PFOS retrieved from the literature (NR not reported). Figure S1. Box-plots of TMF values for PFOS: comparison of TMF values. Figure S2. Variations in gammarid isotope ratios during a 1-year cycle. Figure S3. Variations of $\delta^{13} \mathrm{C}$ and $\delta^{15} \mathrm{~N}$ during field exposure (the subscript TO points to measurements before exposure, while the subscript fin points to measurements at the end of field exposure). Figure S4. Nationwide distribution of TLs estimated in Gammarus spp. (1 pool per site, $N=93$ sites). Table S6. Summary of TL distribution in Gammarus spp. (1 pool per site, $N=93$ pools). Table S7. Nationwide TL distribution of selected fish species.

\section{Abbreviations}

EQS: Environmental Quality Standard, as defined in the Water Framework Directive; LQ: Limit of quantification; PFOS: Perfluorooctane sulfonate (CAS \#1763-23-1), a mixture of linear and branched isomers; PS: Priority substance, as defined in the Water Framework Directive; TL: Trophic level; TMF: Trophic magnification factor; WFD: Water Framework Directive, i.e., Directive 2000/60/ EC of the European Parliament and of the Council of 23 October 2000 establishing a framework for Community action in the field of water policy.

\section{Acknowledgements}

We thank the staff of BIOMAE (Biosurveillance de la qualité de l'eau et des milieux aquatiques, Chateau-Gaillard, France), and Nicolas DELORME and Laura GARNERO (INRAE, RIVERLY, Ecotoxicology laboratory) for their proactive assistance for fieldwork and handling of samples. Erik BONJOUR and Anthony ANCHISI managed isotopic ratio analysis. We also thank Glen MCCULLEY (Metaform Langues, Clermont-Ferrand, France) for copy-editing the manuscript.

\section{Authors' contributions}

MB: study design, data processing, writing. BJDF: method design, writing, reviewing. PJ: isotopic ratio analysis and interpretation. AA and FL: PFOS analysis, data processing. NH-T: interpretation, writing. Cecile MIEGE: study design and coordination, data management, reviewing. OP: study design, writing, reviewing. All authors read and approved the final manuscript.

\section{Funding}

Fieldwork and analyses were given grant support by the French Agency for Biodiversity (AFB; Office Français de la Biodiversité, OFB since January 2020) as part of the prospective surveillance network programme for 2018-2019, part B.

\section{Availability of data and materials Not applicable.}

\section{Ethics approval and consent to participate}

Fishing (capture, transport, and disposition) authorization for scientific or monitoring purposes: granted to "Office Français de la Biodiversité" (OFB) regional offices by prefectural decrees from the local authorities. Fish were euthanized with an appropriate dose of eugenol.

\section{Consent for publication}

All authors approved the final manuscript and agreed to its submission to Environmental Sciences Europe.

\section{Competing interests}

The authors declare no competing interest.

\section{Author details}

1 INRAE, RIVERLY, 69625 Villeurbanne, France. ${ }^{2}$ Swiss Centre for Applied Ecotoxicology (Ecotox Center), EPFL ENAC IIE-GE, Station 2, CH-1015 Lausanne, Switzerland. ${ }^{3}$ ISA, Université de Lyon, CNRS, Université Claude Bernard Lyon 1, Institut des Sciences Analytiques, UMR 5280, 5 rue de la Doua, F-69100 Villeurbanne, France. ${ }^{4}$ INERIS, Unité Méthodes et développements en Analyses pour I'Environnement, 60550 Verneuil-en-Halatte, France. ${ }^{5}$ OFB (Office français de la biodiversité, Direction de la Recherche et de l'appui Scientifique), 94300 Vincennes, France.

Received: 14 July 2020 Accepted: 23 September 2020

Published online: 07 October 2020

\section{References}

1. E.P., E.C. (2000) Directive 2000/60/EC of the European Parliament and of the Council of 23 October 2000 establishing a framework for Community action in the field of water policy vol 2000/60, 22 Dec. 2000 edn. Official Journal of the European Communities.

2. E.C. (2008) Directive 2008/105 of The European Parliament and of the Council on environmental quality standards in the field of water policy and amending Directive 2000/60/EC.

3. E.P., E.C. (2013) Directive 2013/39/EU of the European Parliament and of the Council of 12 August 2013 amending Directives 2000/60/EC and 2008/105/EC as regards priority substances in the field of water policy Text with EEA relevance vol 2013/39, 24 Aug. 2013 edn. Official Journal of the European Communities.

4. E.C. (2014) Common Implementation Strategy for the Water Framework Directive (2000/60/EC) - Guidance Document No. 32 on Biota monitoring (The implementation of $\mathrm{EQS}_{\text {BIOTA }}$ ) under the Water Framework Directive. European Union. doi:https://doi.org/10.2779/833200

5. Borgå K et al (2012) Trophic magnification factors: Considerations of ecology, ecosystems and study design. Integr Environ Assess Manag 8:64-84. https://doi.org/10.1002/ieam.244

6. Alric B et al (2019) Multisubstance indicators based on caged gammarus bioaccumulation reveal the influence of chemical contamination on stream macroinvertebrate abundances across France. Environ Sci Technol 53:5906-5915. https://doi.org/10.1021/acs.est.9b01271

7. Besse JP, Coquery M, Lopes C, Chaumot A, Budzinski H, Labadie P, Geffard O (2013) Caged Gammarus fossarum (Crustacea) as a robust tool for the characterization of bioavailable contamination levels in continental waters: towards the determination of threshold values. Wat Res 47:650-660. https://doi.org/10.1016/j.watres.2012.10.024

8. Ciliberti A et al (2017) Caged Gammarus as biomonitors identifying thresholds of toxic metal bioavailability that affect gammarid densities at the French national scale. Wat Res 118:131-140. https://doi.org/10.1016/j. watres.2017.04.031 
9. Filipović Marijić V et al (2016) Investigation of the soluble metals in tissue as biological response pattern to environmental pollutants (Gammarus fossarum example). Chemosphere 154:300-309. https://doi. org/10.1016/j.chemosphere.2016.03.058

10. Lebrun JD, Uher E, Tusseau-Vuillemin MH, Gourlay-Francé C (2014) Essential metal contents in indigenous gammarids related to exposure levels at the river basin scale: Metal-dependent models of bioaccumulation and geochemical correlations. Sci Tot Environ 466-467:100-108. https://doi. org/10.1016/j.scitotenv.2013.07.003

11. Babut M et al (2017) Per- and poly-fluoroalkyl compounds in freshwater fish from the Rhône River: influence of fish size, diet, prey contamination and biotransformation. Sci Tot Environ 605-606:38-47. https://doi. org/10.1016/j.scitotenv.2017.06.111

12. Tlili K, Labadie P, Bourges C, Desportes A, Chevreuil M (2012) Bioaccumulation of polybrominated diphenyl ethers by the freshwater benthic amphipod Gammarus pulex. Arch Environ Contam Toxicol 63:69-76. https://doi.org/10.1007/s00244-012-9751-x

13. Besse J-P, Geffard O, Coquery M (2012) Relevance and applicability of active biomonitoring in continental waters under the Water Framework Directive TrAC-Trend. Anal Chem 36:113-127. https://doi.org/10.1016/j. trac.2012.04.004

14. Lebrun JD, Geffard O, Urien N, François A, Uher E, Fechner LC (2015) Seasonal variability and inter-species comparison of metal bioaccumulation in caged gammarids under urban diffuse contamination gradient: Implications for biomonitoring investigations. Sci Tot Environ 511:501-508. https://doi.org/10.1016/j.scitotenv.2014.12.078

15. AFNOR (2019) Qualité de l'eau-Encagement in situ de gammares pour la mesure de la bioaccumulation de substances chimiques vol XPT 90-721. https://www.afnor.org/en/purchase-a-standard/.

16. Burkhard LP, Borgå K, Powell DE, Leonards P, Muir DCG, Parkerton TF, Woodburn KB (2013) Improving the Quality and Scientific Understanding of Trophic Magnification Factors (TMFs). Environ Sci Technol 47:11861187. https://doi.org/10.1021/es305253r

17. Kidd KA et al (2019) Practical advice for selecting or determining trophic magnification factors for application under the european union water framework directive integr environ assess. Manage 15:266-277. https:// doi.org/10.1002/ieam.4102

18. Post DM (2002) Using stable isotopes to estimate trophic position: models, methods, and assumptions. Ecology 83:703-718. https://doi. org/10.2307/3071875

19. Aquaref (2013) Composés perfluorés (chaine linéaire en C8) - Méthode d'analyse dans les biotes. https://www.aquaref.fr/system/files/Aquar ef_2013_D1b_INERIS_MA46_PFCs_biotes_VF.pdf.

20. Simonnet-Laprade C et al (2019) Evidence for the spatial variability of poly- and perfluoroalkyl substance (PFAS) trophic magnification in
French rivers. Sci Tot Environ 686:393-401. https://doi.org/10.1016/j.scito tenv.2019.05.461

21. Simonnet-Laprade $C$ et al (2019) Biomagnification of perfluoroalkyl acids (PFAAs) in the food web of an urban river: assessment of the trophic transfer of targeted and unknown precursors and implications. Environ Sci-Proc Imp 21:1864-1874. https://doi.org/10.1039/c9em00322c

22. Froese R, Pauly D (2019) FishBase. World Wide Web electronic publication. Www.fishbase.org, Accessed 21 Jun 2019

23. USEPA (2016) Statistical Software ProUCL 5.1.00 for environmental applications for data sets with and without nondetect observations. https:// www.epa.gov/land-research/proucl-software Accessed 15 Jan 2017

24. Babut M, Jame P, Anchisi A, Bonjour E, Delorme N, Miege C (2020) Isotopic ratios in freshwater gammarids (caged) and wild fish from 15 continental sites (2018) and one reference site (2019), Portail Data INRAE (2020). https://doi.org/10.15454/7GBGUQ

25. Miege C, Assoumani A, Lestremau F, Boutet $P$, Recoura-Massaquant $R$, Jubeaux G, Babut M (2020) PFOS and PFOA concentrations in freshwater gammarids (caged) and wild fish from 15 continental sites (2018), Portail Data INRAE (2020). https://doi.org/10.15454/LKZJR4

26. Hette-Tronquart N, Belliard J (2018) Indicateurs du fonctionnement trophique des cours d'eau - approche par l'analyse des isotopes stables vol action 20.

27. EFSA (2008) Perfluorooctane sulfonate (PFOS), perfluorooctanoic acid (PFOA) and their salts Scientific Opinion of the Panel on Contaminants in the Food chain. EFSA J 6:653. https://doi.org/10.2903/j.efsa.2008.653

28. Fliedner A et al (2016) Biota monitoring and the Water Framework Directive-can normalization overcome shortcomings in sampling strategies? Environ Sci Pollut Res 23:21927-21939. https://doi.org/10.1007/s1135 6-016-7442-2

29. Jones PD, Hu W, De Coen W, Newsted JL, Giesy JP (2003) Binding of perfluorinated fatty acids to serum proteins. Environ Toxicol Chem 22:2639-2649. https://doi.org/10.1897/02-553

30. Luebker DJ, Hansen KJ, Bass NM, Butenhoff JL, Seacat AM (2002) Interactions of fluorochemicals with rat liver fatty acid-binding protein. Toxicology 176:175-185. https://doi.org/10.1016/S0300-483X(02)00081-1

31. Ng CA, Hungerbühler K (2013) Bioconcentration of perfluorinated alkyl acids: How important is specific binding? Environ Sci Technol 47:72147223. https://doi.org/10.1021/es400981a

\section{Publisher's Note}

Springer Nature remains neutral with regard to jurisdictional claims in published maps and institutional affiliations.

\section{Submit your manuscript to a SpringerOpen ${ }^{\circ}$ journal and benefit from:}

- Convenient online submission

- Rigorous peer review

- Open access: articles freely available online

- High visibility within the field

- Retaining the copyright to your article

Submit your next manuscript at $\boldsymbol{\nabla}$ springeropen.com 